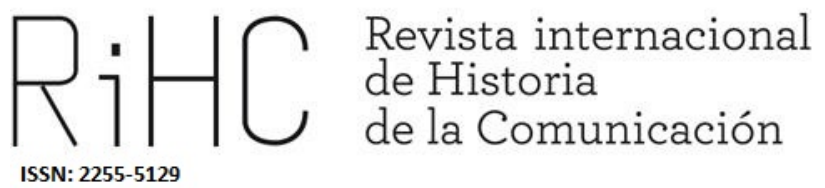

\title{
EL TRATAMIENTO \\ INFORMATIVO DE LA MODA \\ EN LA PRENSA ESPAÑOLA: \\ EL CASO DE DAVID DELFÍN
}

\section{The informative treatment of fashion in Spanish press: David Delfín case}

DOI: http://dx.doi.org/10.12795/RiHC.2018.i10.08

Recibido: $28 / 03 / 2018$

Aceptado: 09/05/2018

Publicado: $25 / 06 / 2018$

Eduardo Villena Alarcón (iD https://orcid.org/0000-0001-8798-8506

Universidad de Málaga, eduardo.villena@uma.es

Resumen: Esta investigación se ocupa del tratamiento informativo de la moda en la prensa española a través del método del estudio de caso. 2017 se recordará como el año en que la moda española despidió al célebre diseñador malagueño David Delfín. Tras él, una trayectoria extraordinaria confirmada con el Premio Nacional de Diseño de Moda 2016 que le fue otorgado por desarrollar un universo vanguardista propio. Sin embargo, esto no siempre fue así. De hecho, su desembarco en Mercedes Benz Fashion Week Madrid estuvo marcado por la controversia que desencadenaron sus creaciones, como así se recogió en la prensa del momento. Por ello, 15 años después y con la 
perspectiva del tiempo, este texto propone un análisis de contenido sobre las noticias y artículos publicados en septiembre de 2002 por los principales diarios españoles con el objetivo de conocer y reflexionar acerca del tratamiento informativo llevado a cabo en aquella ocasión.

Palabras clave: moda, prensa, periodismo especializado.

Abstract: This research focuses on fashion informative treatment in the Spanish press through the case study method. 2017 will be remembered as the year in which Spanish fashion bid farewell to the famous Malaga designer David Delfín. His extraordinary trajectory was confirmed with the 2016 National Fashion Design Award for developing his own avant-garde universe. However, this was not always the case. In fact, his arrival to Mercedes Benz Fashion Week Madrid was marked by the controversy that triggered his creations. Therefore, 15 years later and with the benefit of hindsight, this text proposes a content analysis of the news and articles published in September 2002 by the main Spanish newspapers in order to know what was the treatment of the media in that issue.

Keywords: fashion, press, specialized journalism.

\section{Introducción}

La información especializada en moda sigue siendo un contenido recurrentemente demandado por la sociedad a través de los medios de comunicación. De hecho, es muy habitual que durante los días que se celebran las semanas de la moda, los periódicos dediquen parte de sus espacios a publicar noticias y crónicas acerca de lo acontecido en dichos eventos; al igual que las revistas más prestigiosas publican números especiales con reportajes y contenidos exclusivos.

En las mismas circunstancias que el contenido generalista, la información de moda publicada en los periódicos se desarrolla hoy en un entorno digital que favorece su difusión para todos y cada uno de los demás medios, lo que permite que la audiencia comparta y genere nuevos contenidos. En palabras de García Galindo (2010) el ciudadano es ahora productor de contenido que puede ser difundido públicamente. La tendencia del lector queda reflejada en los datos que arroja el barómetro del Centro de Investigaciones Sociológicas (CIS) al poner de manifiesto en su último informe de 2017 que un 30,5\% de los encuestados leía el periódico en papel o Internet todos o casi todos los días. De igual forma, un $69,4 \%$ respondió que sí seguía contenidos en redes sociales.

Actualmente, y tras la profunda transformación de su encuadre, la información de moda, que se ha visto incrementada en cantidad y calidad, responde en los diarios 
españoles a un modelo centrado en las personas (Paricio Esteban, 2000), ya sean los maniquís o el propio diseñador. Un claro ejemplo de ello fue la tematización de la agenda a partir del polémico desfile protagonizado por el creador David Delfín en 2002. La acción informativa de los medios de comunicación (van Dijk, 2003) contribuyó al deterioro de la imagen de marca del diseñador al haberse condicionado la colección por la contribución de los mass media (Dearing y Rogers, 1996), cumpliendo así la máxima de la agenda setting ${ }^{1}$.

Ahondando en lo anterior, de cómo se presenta el contenido y de los lectores habla Fontcuberta (1993) cuando expone que "el formato de un medio refleja el valor que otorga a las informaciones que presenta, y los receptores interpretan el medio en función de las reglas que él mismo enseña". Sin embargo, teniendo al usuario como centro, Igartua y Humanes (2004) afirman que uno de los principales efectos de la exposición a noticias no es el aprendizaje de los hechos sino saber calibrar lo que es importante en un determinado momento. En contraposición, Pérez Curiel (2013) refleja la opinión de los diseñadores al afirmar que "es un secreto a voces que los creadores de moda califican la labor informativa como falta de rigor y especialización. El desconocimiento técnico de cronistas y críticos es el denominador común de las quejas de los profesionales del diseño".

Por tanto, frente a esta idiosincrasia, y tras el fallecimiento de David Delfín, el consiguiente texto propone analizar el tratamiento informativo que las principales cabeceras de periódico en España le otorgaron a las noticias acaecidas sobre la primera colección que el diseñador presentó en la Pasarela Cibeles ${ }^{2}$ para la primavera/verano de 2003.

Si bien la industria de la información en general ha sido analizada por Laguna y Martínez (2015), el papel de la prensa informativa o la de sucesos ha sido estudiada por Carratalá (2015) y Rodríguez Cárcela (2016) respectivamente en los últimos años. También el tratamiento en otros escenarios, como lo hizo Morales (2016) con la televisión. Igualmente, Sujatovich (2016) centró la mirada en la importancia del editorial como sección propia de los periódicos españoles. Ya de manera específica, el estudio del tratamiento informativo en medios es un tema recurrente en cuestiones relacionadas con la política y otros asuntos públicos. Notables son las aportaciones de McCombs y Shaw (1972) acerca de las funciones de los medios respecto a la agenda; o Scheufele y Tewksbury (2007) sobre el enfoque y su influencia. También merecen especial mención lo aportado por McCombs y Shaw (1993) ó Esrock y Leichty (1998).

\footnotetext{
${ }^{1}$ Teniendo como referencia lo aportado por Aruguete (2009), la hipótesis inicial de la Agenda Setting es que los medios de comunicación tienen la capacidad de seleccionar y destacar ciertos temas y omitir otros $y$, mediante ese mecanismo, instalar los asuntos que son percibidos como importantes por la opinión pública.

${ }^{2}$ Desde 2012 la Pasarela Cibeles recibe el nombre de Mercedes Benz Fashion Week Madrid al tener a la marca de automóviles como patrocinadora oficial.
} 
Finalmente, la información sobre moda ha sido tratada en los últimos años desde diferentes perspectivas. Cabe destacar el trabajo de Velasco Molpeceres (2016) con respecto a la moda femenina y la prensa en el siglo XIX. El papel circunscrito de la mujer en la prensa de esa época fue tratado por Cantizano (2004) o Gallego (2008), al igual que la evolución hasta las revistas que hoy conocemos quedó explicada por Menéndez y Figueras (2013). De su crisis postuló Ganzabal (2006) y de su publicidad, Díaz de Soloaga (2007) ó Gómez de Travesedo (2017); algo que ya avanzó Cristófol y Méndiz (2010) cuando argumentaron el género híbrido. Por último, los contenidos también han sido empresa de Torres (2007) ó Garrido (2008).

\section{David Delfín, el hombre total de la moda}

El modisto español David Delfín había sido galardonado con el Premio Nacional de la Moda 2016 por la audacia, valentía y compromiso social de su obra, con una señalada identidad española ${ }^{3}$. No llegó a recogerlo. Falleció el 3 de junio de 2017. Probablemente, Diego David Domínguez González no se hubiera imaginado en 2001, cuando creó la firma David Delfín junto a Diego y Gorka Postigo y Bimba Bosé, que, casi 20 años después, se convertiría en una figura indispensable en el panorama textil español. Tampoco que su obituario iba a estar marcado por el reconocimiento como hombre total de la moda ${ }^{4}$; mucho menos después de haber protagonizado las noticias más escandalosas que se recuerda tras su polémico desfile de 2002. Esto refutó lo que Pérez y Luque (2014) postularon al decir que la moda interesa a las grandes empresas de medios de comunicación.

Un año antes, en 2001, el creador había debutado en la pasarela Circuit de Barcelona (VV.AA., 2013) con la colección Openin Nite para la primavera/verano 2002. Le continuó su colección “\#2" para otoño/invierno 2002/2003. En 2002 dio el salto a la antigua Pasarela Cibeles y se le acusó de misógino por el desfile Cour des Miracles para la temporada otoño/invierno de 2003. Tras aquella polémica irrupción, Delfín fue edición tras edición el desfile más aclamado de la semana de la moda madrileña y vistió a todas las grandes celebrities de nuestro país ${ }^{5}$. No hubo que esperar demasiado, un año después, y a pesar del escándalo, obtuvo el premio L'Oreal al joven diseñador gracias a la colección In Loving Memory. Su popularidad alcanzó cotas máximas a

\footnotetext{
${ }^{3}$ David Delfín, Premio Nacional de Diseño de Moda. (18 de noviembre de 2016). El País. Disponible en: https://elpais.com/elpais/2016/11/18/estilo/1479471223_971087.html

${ }^{4}$ Montero, S. (4 de junio de 2017). El hombre total de la moda. El Mundo, p. 58.

${ }^{5}$ El diseñador David Delfín fallece a los 46 años. (4 junio 2017). Europa Press. Disponible en: http://www.europapress.es/cultura/noticia-disenador-david-delfin-fallece-46-anos20170604002111.html
} 
principio de los dos mil cuando la revista Telva lo nombró en 2006 mejor diseñador nacional. Ya para entonces, y desde el punto de vista editorial y académico, había despertado el interés de los investigadores. Además de ser parte implicada de diferentes publicaciones, el diseñador fue objeto de investigación cuando del Olmo y Fondevila (2014) destacaron su posicionamiento SEM como un ejemplo para las empresas de moda, analizando sus enlaces patrocinados y la estructura de los mismos.

La publicación del fenecimiento le devolvió a la actualidad, lo que tematizó la agenda con informaciones relacionadas con la moda durante varios días. Con titulares como "Adiós al modisto transgresor"6, "Un delfín entre las olas"7 ó "El sastrecillo valiente" la prensa española despidió al diseñador. "La sangre abierta de la libertad" 9 fue como nominó Luis María Ansón al modisto en el suplemento cultural de El Mundo. De él escribió que "era el fulgor en la pasarela, la tijera incandescente, el aspaviento de la provocación". Finalmente, "El creador total", como tituló el obituario de La Vanguardia en una media página a cinco columnas, obtuvo un reconocimiento generalizado, pero tal y como hemos comprobado, no siempre fue así.

\section{Objetivos y metodología}

El presente artículo analiza el tratamiento informativo que los principales diarios españoles dieron a David Delfín con motivo de su desfile en la antigua Pasarela Cibeles el 13 de septiembre de 2002. Los periódicos escogidos son los siguientes:

Tabla 1. Periódicos seleccionados en función de la difusión

\begin{tabular}{|ll|}
\hline Cabecera & Lectores/día \\
\hline El País & 1.603 \\
\hline El Mundo & 1.075 \\
\hline$A B C$ & 813 \\
\hline
\end{tabular}

\footnotetext{
${ }^{6}$ Muere a los 46 años David Delfín (4 de junio de 2017). El Periódico, p. 85.

${ }^{7}$ Izaguirre, B. (5 de junio de 2017). Un delfín entre las olas. El País, p. 36.

${ }^{8}$ Iturrialde, T. (5 de junio de 2017). David Delfín. El sastrecillo valiente. El Mundo, p. 5.

${ }^{9}$ Ansón, L.M. (23 de junio de 2017). David Delfín la sangre abierta de la libertad. El Cultural, p. 3.
} 


\begin{tabular}{|ll|}
\hline El Periódico & 764 \\
\hline La Vanguardia & 629 \\
\hline La Razón & 323 \\
\hline
\end{tabular}

Fuente: Elaboración propia a partir de EGM

El criterio de selección de las cabeceras citadas responde al número de lectores por día de los seis principales periódicos generalistas de España en el año móvil febreronoviembre de 2002 (ver Tabla 1). En consecuencia, los objetivos prioritarios de la investigación se resumen en:

1. Cuantificar las informaciones sobre David Delfín publicada en los periódicos.

2. Descubrir los factores que definieron la tematización de la agenda acerca del tema.

3. Mostrar la importancia mediática que cada uno concede al tema objeto de estudio.

También, para alcanzar los objetivos propuestos, partimos de las siguientes hipótesis:

- H1. La información sobre Cibeles se personaliza en la figura del diseñador David Delfín, formando parte de la agenda de la prensa como sujeto propio.

- H2. Las piezas informativas a cerca de David Delfín tienen un estilo informativo carente de tecnicismos fruto de la falta de especialización.

Gracias al estudio de caso y a través de la metodología seleccionada, el análisis de contenido, se ha podido cuantificar y analizar el tratamiento informativo que realizan los diarios mencionados. En palabras de Wimmer y Dominick (1996), esta técnica permite estudiar las noticias publicadas de una forma sistemática, objetiva y cuantitativa. Asimismo, nos ha permitido formular, a partir de ciertos datos, inferencias reproducibles y válidas que pueden aplicarse al contexto (Krippendorff: 1990; Bardin, 1996).

Para la selección de las piezas informativas se recurrió a la base de datos My News que posibilitó la búsqueda por la palabra clave "David Delfín" desde el 13 de septiembre de 2002 hasta el 30 del mismo mes. Conforman pues la muestra un total de 54 noticias publicadas en todas las secciones de los periódicos incluidos en el estudio en septiembre de 2002.

Por último, una vez localizadas las piezas que tuvieran como tema principal el desfile del diseñador; y elegida la metodología, se aplicó sobre cada unidad informativa una plantilla de análisis cuyos ítems responden a lo postulado por Lazcano (2013), Cervantes (1996), Pérez Curiel (2013), Prieto (2013) ó Rodríguez (2016). 
Particularmente, las variables que se incluyen en el estudio son: Número de la noticia; Nombre del Diario; Fecha de publicación; Autoría: Redactor/a, Agencia, Sin firma; Género periodístico: Noticia, Crónica, Reportaje, Entrevista, Opinión, Otros; Sección: Nacional, Local, Sociedad, Cultura, Opinión, Otros; Enfoque: Técnico, Hecho de Actualidad, Otros; Titular: Enfocado a Cibeles, Enfocado a Delfín.

Completa la investigación una revisión documental sobre los diarios antes especificados que tuvo como objeto la muerte de David Delfín en junio 2017 y que sirvió para contextualizar al diseñador.

Finalmente, y retomando lo expuesto en el epígrafe anterior de introducción, aunque la información sobre moda haya sido tratada a lo largo de estos últimos años desde diferentes perspectivas, son exiguas las investigaciones que tienen su tratamiento informativo como objeto; por lo que la pertinencia del texto viene avalada por la necesidad de conocer cómo el sector queda reflejado en la prensa, así como ofrecer un texto de referencia que aporte una nueva línea investigadora al asunto.

\section{Resultados}

A través del estudio de caso de David Delfín en la prensa española, la investigación planteada arroja los siguientes datos en torno al tratamiento informativo de la moda.

Del total de las piezas analizadas, un 30\% corresponden a El Mundo, seguido de $A B C$ (26\%), El Periódico (22\%), El País (18\%) y La Vanguardia (4\%). El único diario que no se ocupa de lo acontecido en Cibeles es La Razón, que no publica ninguna pieza informativa al respecto (Ver Gráfico 1).

Gráfico 1. Número de noticias por cabecera 


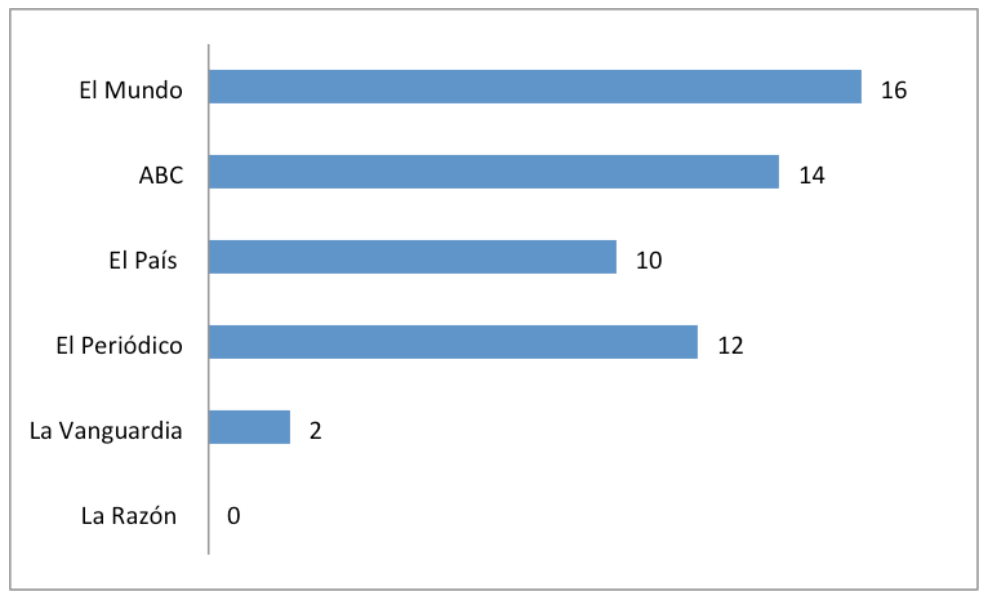

Fuente: Elaboración propia

El hecho objeto de estudio tematiza la agenda desde el 14 de septiembre de 2002, día después del polémico desfile, hasta el jueves 26 del mismo mes, fecha en la cual se deja de tratar el asunto. El mayor número de piezas (10) se publica los primeros tres días tras el evento y el interés va decayendo de manera discontinua a lo largo de la semana, tal y como podemos observar en el Gráfico 2. Particularmente, de la investigación se desprende que la noticia tiene especial repercusión en prensa en los números publicados durante el fin de semana; de hecho, el escándalo tiende a morir hasta que se reactiva de nuevo en el segundo fin de semana señalando un segundo pico informativo.

\section{Gráfico 2. Calendario de publicaciones}

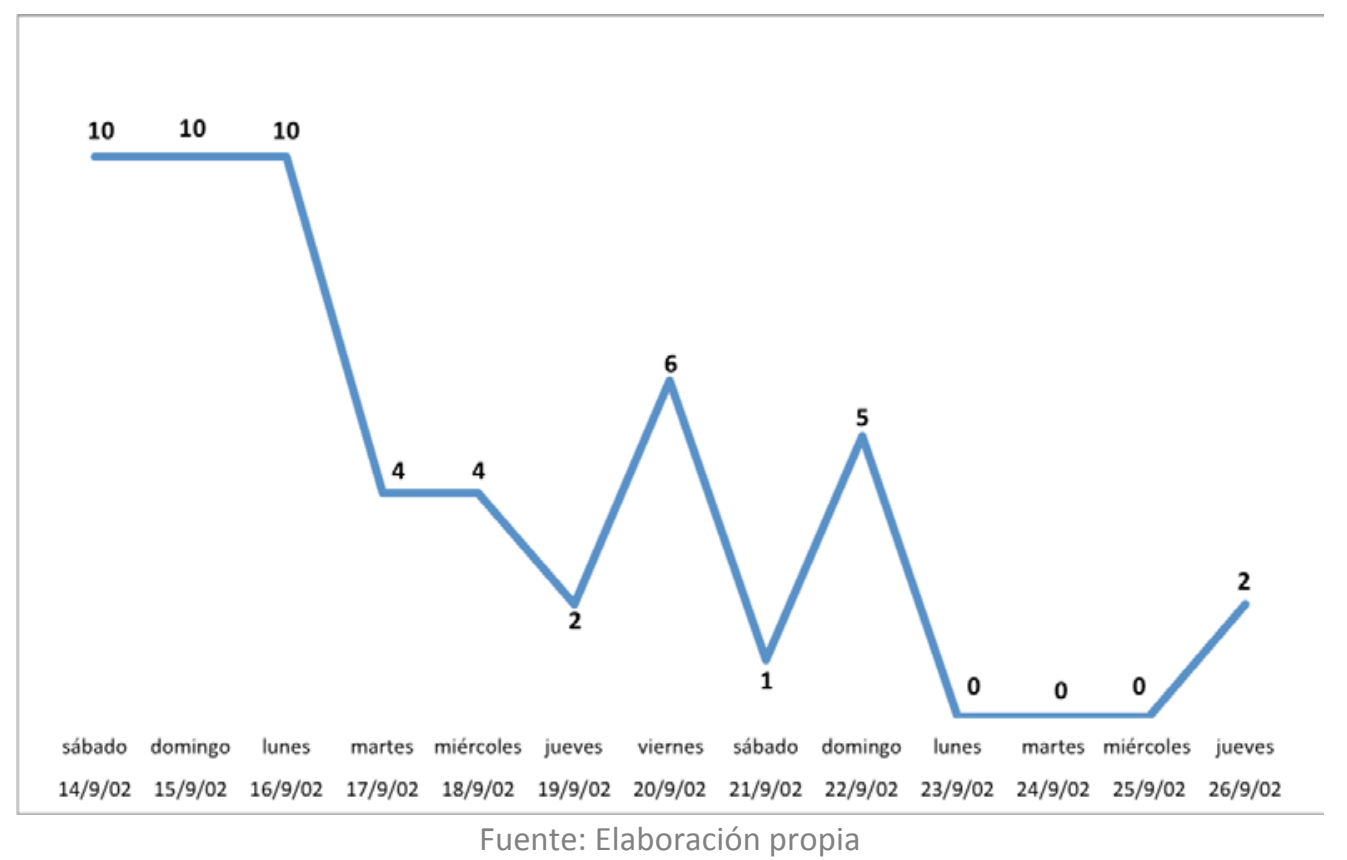

Si atendemos al número de publicaciones que cada periódico lanzó cada jornada, podemos observar que durante los primeros tres días se hace un esfuerzo informativo por parte de El Mundo, ABC, El Periódico, El País y La Vanguardia. El día 14, El Mundo 
publica 4 piezas frente $A B C$ y El País que publican 2. El Periódico y La Vanguardia por su parte optan por 1 sola noticia. El pico informativo aumenta en el segundo día por parte de $A B C$ y $E I$ Periódico, y se reduce notablemente en El Mundo, que vuelve a apostar por el contenido referente a Cibeles el lunes 16.

Gráfico 3. Calendario de publicaciones por medio

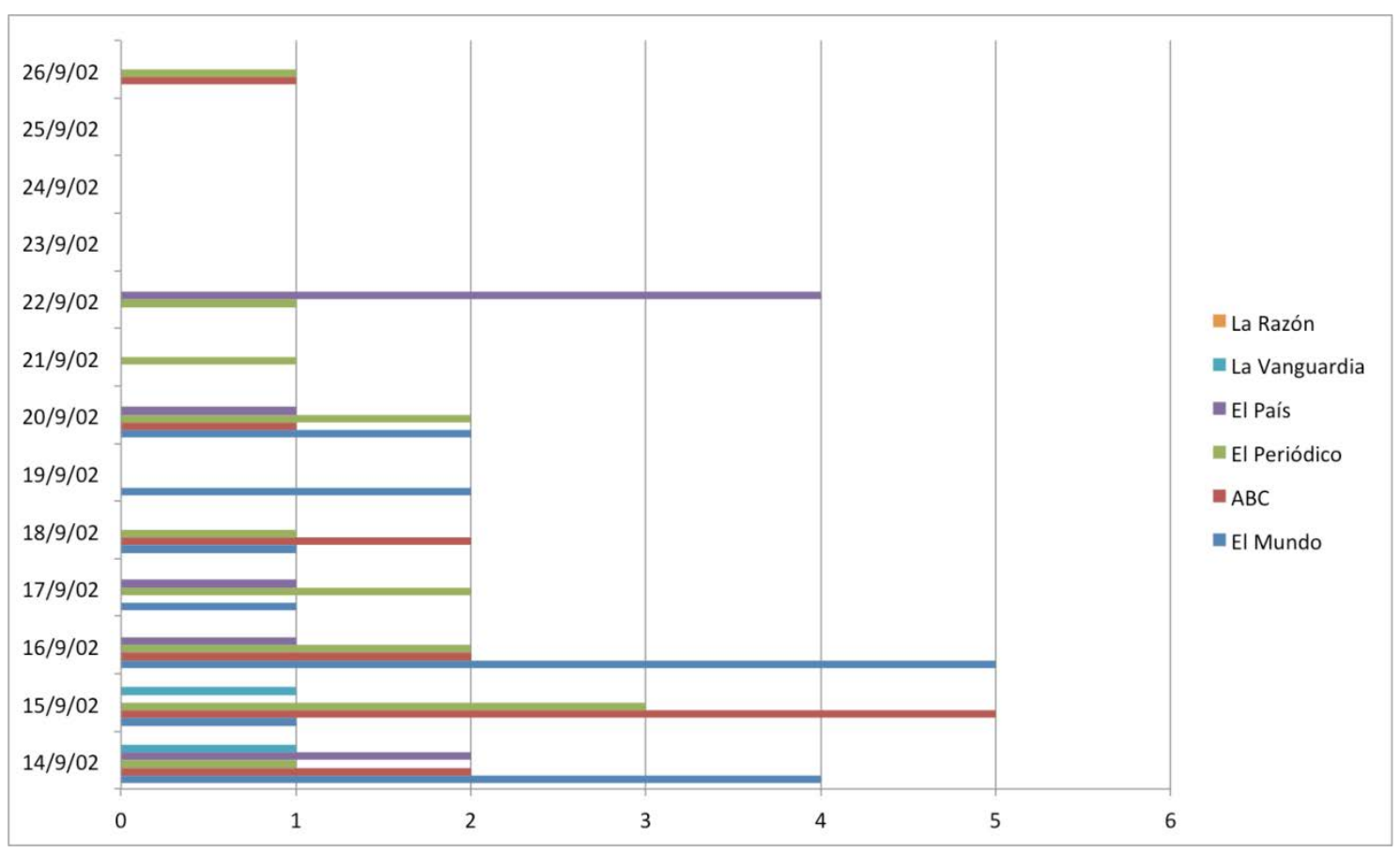

Fuente: Elaboración propia

Respecto a la posición de las unidades de análisis dentro de las diferentes secciones de los periódicos estudiados, podemos observar que éstas se sitúan habitualmente en los espacios dedicados a opinión (35\%), sociedad (24\%), local (22\%), cultura (9\%) y otros (9\%). Del total, tan solo El País y El Mundo llevaron sendas piezas a portada.

Gráfico 4. Secciones dedica 


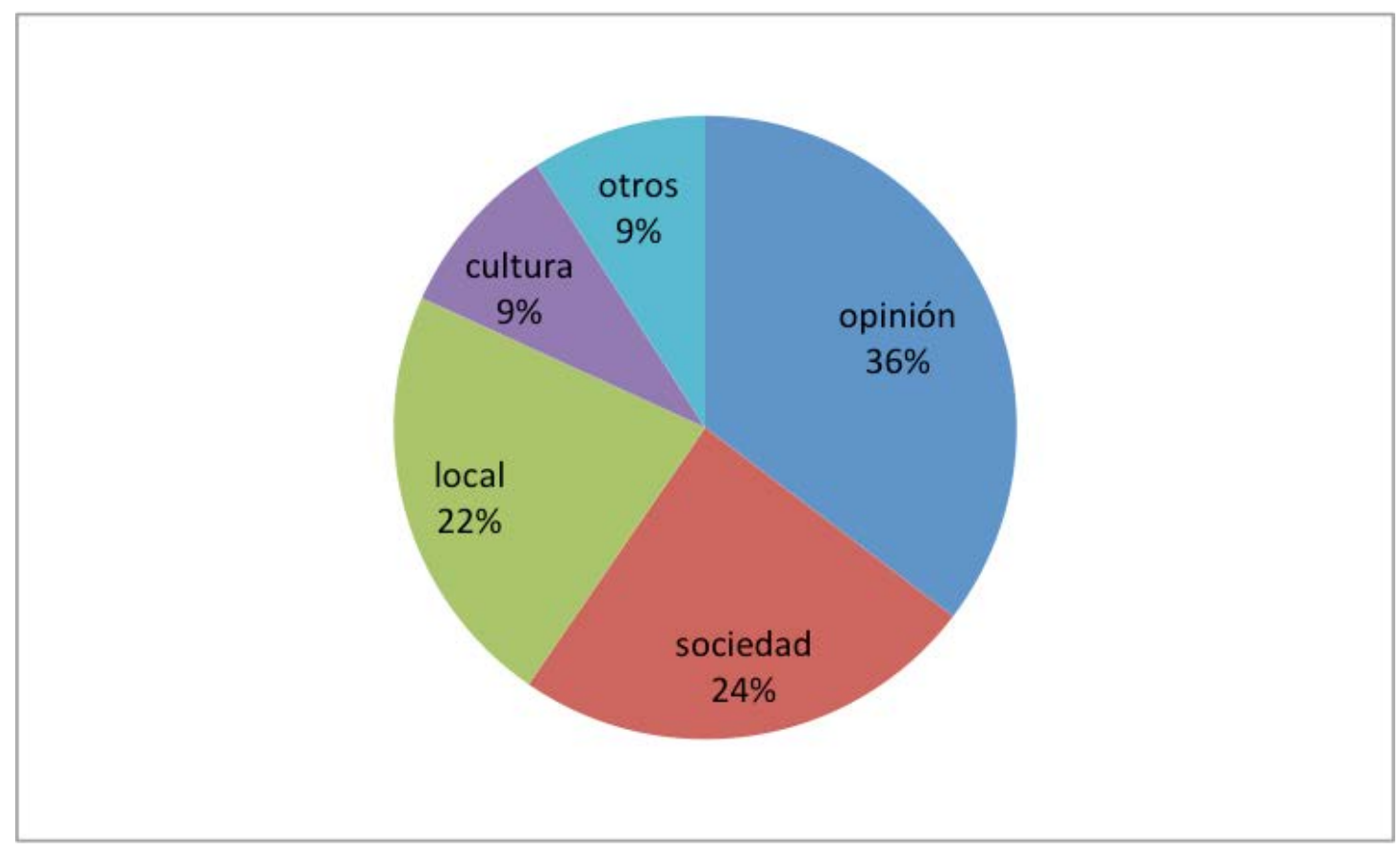

Fuente: Elaboración propia

Centrados en el titular, el $22 \%$ de ellos tienden a citar al diseñador frente a un $78 \%$ que centra su interés en lo acontecido en Cibeles. El Mundo y $A B C$ son los periódicos que más se ocupan de la figura del creador, seguido de El País. Como se ha especificado en líneas anteriores, la continuidad de la noticia estuvo marcada por la actualidad de los acontecimientos, produciendo una cobertura en río los primeros tres días tras el desfile (ver Gráfico 2). De igual forma, los suplementos y espacios de fin de semana vuelven a tematizar la agenda generando un nuevo pico informativo.

El escándalo surge como elemento noticioso (7\%) pero pasa rápidamente a los espacios de opinión (39\%). Destaca como género periodístico propio de la información especializada en moda la crónica (50\%), seguido del breve (40\%), la entrevistas (4\%) y el reportaje (3\%). 


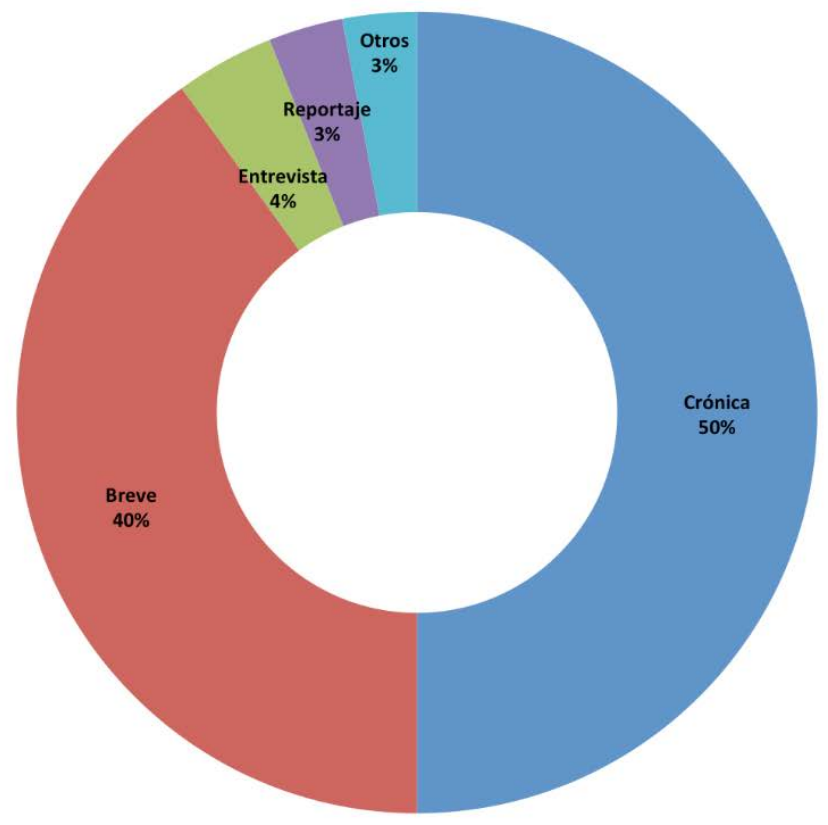

Fuente: Elaboración propia

Las piezas informativas adolecen de un enfoque técnico (7\%) a favor de un tratamiento propio de actualidad marcado por la opinión y la crónica como género predominante sin enfoque claro y carente de tecnicismos. En última instancia, se contrapone el periodismo de actos programados (18\%) de los primeros días frente al periodismo de mesa (82\%) de las sucesivas jornadas. Respecto a la autoría, un $15 \%$ de las noticias aparecen sin firmar frente al $50 \%$ de los redactores y el $35 \%$ de las redactoras que marcan su autoría. Destaca la ausencia de agencias si no es para aportar fotografías. Las unidades analizadas carecen de fuentes en un $28 \%$. El $17 \%$ que tiene más de una y el $55 \%$ que tiene más de dos.

\section{Conclusiones}

Una vez obtenidos los resultados acerca del tratamiento informativo que los principales diarios españoles dieron a David Delfín con motivo de su desfile en la antigua Pasarela Cibeles el 13 de septiembre de 2002, se pueden establecer ciertas conclusiones.

En primer lugar, en contra de la hipótesis que se había enunciado en el apartado metodológico, la información publicada sobre Cibeles no se personaliza en la figura del diseñador David Delfín, sino que se trata de forma global dentro de la crónica habitual de la pasarela. Sin embargo, el creador sí forma parte, a partir de entonces, de la 
agenda de la prensa como sujeto propio. Por el contrario, sí se ha logrado verificar la segunda hipótesis. Es decir, las piezas informativas sobre David Delfín tienen un estilo informativo carente de tecnicismos y especializaciones al estar enmarcado en un acontecimiento de actualidad.

Por último, cabe destacar el compromiso manifiesto de El Mundo con la información relacionada con la moda, al igual que el desapego de La Razón con este tipo de contenido. En el término medio, entusiasma el esfuerzo informativo llevado a cabo por El Periódico dada la naturaleza del medio al igual que resulta desalentador la escasa relevancia del hecho informativo para El País.

Finalmente, la consecuente investigación constata la necesidad evidente de trabajar la información de moda desde una perspectiva profesional y profesionalizada cuyo contenido sea especializado y profundo, al igual que las noticias que son objeto de otras secciones.

De cualquier forma, al margen de las limitaciones propias de este tipo de metodología, son futuras investigaciones aquellas llamadas a conocer la cobertura total que los diferentes periódicos han realizado de David Delfín y su trabajo creativo a lo largo de los 15 años de profesión; así como la evolución en su tratamiento.

\section{Referencias bibliográficas}

ARUGUeTE, N. (2009): "Estableciendo la agenda. Los orígenes y la evolución de la teoría de la Agenda Setting", en Ecos de la comunicación, 2(2). Disponible en: http://bibliotecadigital.uca.edu.ar/repositorio/revistas/estableciendo-laagenda.pdf

BARDIN, L. (1996): Análisis de contenido, Ediciones Akal.

CANTIZANO, B. (2004): "La mujer en la prensa femenina del XIX", en Ámbitos: Revista internacional de comunicación, $\mathrm{n}$ 0 11-12.

CARRATALÁ, A. (2014): “El Crimen de la Calle Fuencarral (1888) la incursión judicial de la prensa como acusación popular en los inicios del sensacionalismo en España", en Revista internacional de Historia de la Comunicación, no 5, pp. 1-16.

CERVANTES BARBA, C. (1996): "Construcción primaria del acontecer y planeación de la cobertura informativa: propuesta metodológica para su estudio", en Comunicación y Sociedad, no 28. 
CRISTÓFOL, C. Y MÉNDIZ, A. (2010): “Nuevas estrategias de creación de imagen en las marcas de moda: La hibridación de información y publicidad en los contenidos de las revistas femeninas", en De Pablos, J.M. (ed.). Libro de actas del II Congreso Internacional Latina de Comunicación Social, Tenerife, Universidad de La Laguna.

DEARING, J.W. y ROGERS, E.M. (1996): Agenda setting, Madrid, Síntesis.

DEL OLMO, J.L. Y FONDEVILA GASCÓN, J.F. (2014): Marketing digital en la Moda, Pamplona, Ediciones Universidad de Navarra.

DÍAZ SOLOAGA, P. (2007): "Valores y Estereotipos Femeninos Creados en la Publicidad Gráfica de las Marcas de Moda de Lujo en España", en Anàlisi, Quaderns de Comunicaciò i Cultura, no 35, Barcelona, Universidad Autónoma.

ESROCK, S.L. y LEICHTY, G.B. (1998): "Social Responsibility and Corporate Web Pages: Self-Presentation or Agenda-Setting?", en Public Relations Review, 24 (3), pp. 305-19.

FONTCUBERTA, M. (1993): La noticia. Pistas para percibir el mundo, Barcelona, Paidós.

GALLEGO AYALA, J (2008): "La prensa femenina: una cala difícil abordaje", en Fernández Sanz, J.J. (Coord.), Prensa especializada actual: doce calas, Madrid, McGraw-Hill, pp. 131-175.

GANZÁBAL, M. (2006): “Nacimiento, remodelación y crisis de la prensa femenina contemporánea en España. (2006)", en Revista Latina de Comunicación Social, 61. Disponible en: http://www.ull.es/publicaciones/latina/200615Ganzabal.htm

GARRIDO, M. (2008): “Contenidos dominantes en las revistas femeninas de alta gama”, en Comunicación y pluralismo, (5), 61-85, Universidad Pontificia de Salamanca.

GÓMEZ DE TRAVESEDO, R. (2017): "La publicidad de moda en las revistas femeninas de alta gama en España en 2014", en Herrero, FJ. y Mateos, C. (eds.): “Del verbo al bit", pp. 1846-1863.

IGARTUA, J.J. y HUMANES, M.L. (2004): Teoría e investigación en comunicación social, Madrid, Síntesis.

KRIPPENDORFF, K. (1990): Metodología de análisis de contenido: teoría y práctica, Barcelona, Paidós.

GARCÍA GALINDO, J.A. (2010): “La opinión pública en la Sociedad de la Información: un fenómeno social en permanente cambio", en Brocar: Cuadernos de investigación histórica, 34, 273-288. 
LAGUNA, A y MARTíNEZ, F.A. (2015): "Pioneros de la industria de la información española", en Revista Internacional de Historia de la Comunicación, ํㅜㄴ, Vol.1, pp. 1-21.

LAZCANO, D. (2013): "Análisis de la cobertura periodística de La Vanguardia y $A B C$, sobre la creación de las facultades de ciencias de la información en España (curso académico 1971-1972)", en Revista internacional de Historia de la Comunicación, no 1, Vol. 1, pp. 176-199.

MCCOMBS, M.E. y SHAW, D.L (1972). "The agenda-setting function of mass media”, en Public Opinion Quarterly, 36, pp. 176-185.

MCCOMBS, ME. Y SHAW, D.L. "The Evolution of Agenda-Setting Research: Twenty-Five Years in the Marketplace of Ideas", en Journal of Communication, 43(2), pp. 5867.

MENÉNDEZ, M.I. Y FIGUERAS, M. (2013): "La evolución de la prensa femenina en España: de La Pensadora Gaditana a los blogs", en Revista de Recerca i d'Anàlisi, 20(1), pp. 25-48.

MORALES, G. (2016): "Estudio del tratamiento periodístico del acontecer sociopolítico en noticias de televisión", en Opción, Año 32, No. Especial 10 (2016), pp. 304325.

PARICIO ESTEBAN, P. (2000): "El encuadre de la moda en los diarios españoles de información general de ámbito nacional (1900-1994)", en Revista Latina de Comunicación Social, 28. Disponible en: http://www.ull.es/publicaciones/latina/aa2000sab/119paricio.html

PÉREZ CURIEL, C Y LUQUE ORTIZ, S. (2014): “La infoxicación de los grupos de poder en las publicaciones de moda. análisis de la contaminación de grandes empresas en los medios de comunicación". en Primer Congreso Internacional Infoxicación: mercado de la información y psique, Libro de Actas, pp. 937-952.

PÉREZ CURIEL, C. (2013): “Expertos en comunicación y moda. Calidad profesional en tiempos de crisis", en Correspondencias y Análisis, no 3.

PRIETO LÓPEZ, M. (2013): "El tratamiento informativo en los medios", en Revista Internacional de Historia de la Comunicación, no 1, Vol. 1, pp. 200-224

RODRÍGUEZ CARCELA, R.M (2016): "La prensa de sucesos en el periodismo español". en Revista Internacional de Historia de la Comunicación, no 6, Vol. 1, pp. 22-44.

SUJATOVICH, L. (2016): "El editorial como espacio convocante a nuevos lectores: la agenda temática de la nación argentina (1862-1869)", En Revista Internacional de Historia de la Comunicación, №6, Vol.1, pp. 45-60. 
TORRES, R (2007): “Revistas de moda y belleza: el contenido al servicio de la forma bella" en Ámbitos: Revista internacional de comunicación, (16), 213-225. Recuperado de http://grupo.us.es/grehcco/ambitos_16/11torres.pdf

VAN DIJK, T. (2003). "La multidisciplinaridad del Análisis Crítico del Discurso: un alegato a favor de la diversidad", en WODAK, R. Y MEYER, M (eds.), Métodos de análisis crítico del discurso, Barcelona, Gedisa, pp. 143-177.

VELASCO MOLPECERES, A.M. (2016): Moda y prensa femenina en España (siglo XIX), Madrid, ediciones19.

VV. AA. (2003): España de Moda, Segovia, Artec.

WIMMER, R. D. Y DOMINICK, J. R. (1996): La investigación científica de los medios de comunicación. Una introducción a sus métodos, Barcelona, Bosch. 